\title{
1 Physical and mechanical properties of lactose/WPI mixtures: effect of pre-
}

\section{crystallisation}

3

4

5

6

7 Runjing $\mathrm{Li}^{\mathrm{a}, \mathrm{b}}$, Yrjö H. Roos ${ }^{\mathrm{b}}$, Song Miao ${ }^{\mathrm{a} *}$

8

9

10

11

12

13

${ }^{a}$ Teagasc Food Research Centre, Moorepark, Fermoy, Co. Cork, Ireland

14

${ }^{b}$ School of Food and Nutritional Sciences, University College Cork, Cork, Ireland

15

16

17

18

19 *Corresponding author. Tel.: +3532542468

20

E-mail address: song.miao@teagasc.ie (Song Miao)

21 
ABSTRACT

This study investigated the physical and mechanical properties of spray-dried lactose/whey protein isolate (WPI) (4:1) mixtures with different contents of $\alpha$-lactose monohydrate $(1.0 \%$, $11.2 \%, 29.2 \%$, and $46.8 \%$, w/w). Particle size of samples with $11.2 \%, 29.2 \%$, and $46.8 \%$ crystallinity was significantly $(P<0.05)$ larger compared with the sample with $1.0 \%$ crystallinity. The presence of less than $46.8 \%$ crystalline lactose in lactose/WPI mixtures had only a minor effect on water sorption behaviour at $\mathrm{a}_{\mathrm{w}} 0.11-0.44$, whereas samples with higher crystallinity had higher stable water content after showing lactose crystallisation. Moreover, samples with lower crystallinity showed higher initial sorption rates. Increasing the amount of crystalline lactose had no significant influence on the glass transition temperature and the initial crystallisation temperatures at $\mathrm{a}_{\mathrm{w}} 0.11-0.44$. Furthermore, dairy powders with higher crystallinity had higher stiffness and water plasticisation showed a stronger effect on the structural relaxation of dairy powders with lower crystallinity.

37

38 


\section{Introduction}

The main carbohydrate in dairy powders is lactose (Arellano, Aguilera, \& Bouchon, 2004), which can exist in various crystalline and non-crystalline forms. The crystalline state is a solid state, having molecules well arranged in regular lattice. According to Haque and Roos (2005), the main types of crystallised lactose are $\alpha$-lactose monohydrate, anhydrous $\beta$ lactose, and anhydrous forms of $\alpha$ - and $\beta$-lactose in molar ratios of 5:3 and 4:1. Compared with lactose in the crystalline state, the molecular arrangement of lactose in the amorphous state is disordered. Moreover, amorphous lactose is thermodynamically unstable and hygroscopic, easily absorbing moisture from the surroundings and then plasticising, while the crystalline lactose is thermodynamically stable and much less hygroscopic. These different state forms affect the behaviour of lactose and materials containing lactose, such as dairy powders (McSweeney \& Fox, 2009). There has been considerable interest in amorphous components in dairy and pharmaceuticals industries. The presence of even small amounts of amorphous components can have a significant impact on the physico-chemical properties of materials, and subsequently alter product performance (Buckton \& Darcy, 1996). According to Bronlund and Paterson (2004) and Ibach and Kind (2007), the amorphous form of lactose has a much higher water content at a given humidity than the crystalline form and Hogan and Buckton (2001) stated that water sorption can be used to quantify the amorphous content of predominantly crystalline materials. In addition, Bronlund and Paterson (2004) indicated that the amount of water sorbed by crystalline powders at high water activity was dependent on the packing density of the powder particles, and small quantities of amorphous lactose present on crystalline powders caused significant changes to the water sorption behaviour. 
In dairy powders, amorphous solids have a liquid-like structure with an extremely

high viscosity. The amorphous residue will be changed to a nonequilibrium liquid state when temperature increases. Under the same thermodynamic conditions amorphous solids display higher molecular mobility than crystalline solids (Liu, Bhandari, \& Zhou, 2006). The molecular mobility of the amorphous components is of great importance in determining the physical stability of food materials (Hancock, Shamblin, \& Zografi, 1995). When the temperature increases from below to above the glass transition temperature $\left(T_{g}\right)$, many of the physical properties of the amorphous materials show a rapid change, including increases in the free volume, molecular mobility, and dielectric coefficient. Additionally, large changes in viscoelastic properties of amorphous powders were expected above $T_{g}$ (Jones, 1999; Kasapis, 2001; Royall et al., 2005). Crystallisation of amorphous components in food products may enhance both physical and chemical stability (Berlin, Anderson, \& Pallansch, 1968a, 1968b; Miao \& Roos, 2004; Roos \& Karel, 1991), and changing the crystallinity of lactose in dairy powders often affects product quality (Aguilar \& Ziegler, 1994; Roos, Jouppila, \& Söderholm, 1999).

Water sorption behaviour, crystallisation and glass transitions of amorphous lactose, amorphous lactose/protein systems and amorphous lactose/salts mixtures after freeze-drying or spray drying have been widely studied (Bandyopadhyay, Das, \& Sharma, 1987; Berlin, Anderson, \& Pallansch, 1968a,b, 1970; Foster, Bronlund, \& Paterson, 2005; Haque \& Roos, 2004a,b, 2005, 2006; Haque, Kawai, \& Suzuki, 2006; Hermansson, 1977; Hogan \& Buckton, 2001; Jouppila, Kansikas, \& Roos, 1997; Kaminaski \& Al-Bezweni, 1994; Potes, Kerry, \& Roos, 2012; Shrestha, Howes, Adhikari, \& Bhandari 2007). Moreover, the amounts of crystalline lactose can affect the sorption behaviour of lactose powders significantly (Bronlund \& Paterson, 2004). However, there has been no further study about the effects of crystalline lactose content on mechanical properties of dairy powders, which is essential for 
dairy research and industry. The objectives of this study were to determine the influence of crystalline lactose content on physical and mechanical properties of lactose/ whey protein isolate (WPI) mixtures.

\section{Materials and methods}

\subsection{Materials}

Powdered of $\alpha$-lactose monohydrate (> 99\% purity) was kindly donated by Arla Foods Ingredients (Viby J, Denmark). WPI, containing 71\% $\beta$-lactoglobulin and $12 \% \alpha-$ lactalbumin, was obtained from Davisco Food International (Le Sueur, MN, USA). Aluminium oxide calcined powder was purchased from Sigma-Aldrich (St. Louis, MO, USA).

\subsection{Sample preparation}

Lactose/WPI (4:1) mixtures at 40\% (w/w) dry matter were prepared in de-ionised water at $65{ }^{\circ} \mathrm{C}$ in a water bath for $2 \mathrm{~h}$ with a stirring speed of $500 \mathrm{rpm}$. These solutions were kept at room temperature $\left(20-22{ }^{\circ} \mathrm{C}\right)$ with a stirring speed of $150 \mathrm{rpm}$ for $0,3,15$ and $20 \mathrm{~h}$ pre-crystallisation; these lactose/WPI mixtures were defined as S1, S2, S3 and S4, respectively, according to the pre-crystallisation time. After pre-crystallisation, samples were spray-dried using an ANHYDRO spray dryer with a centrifugal atomiser (Copenhagen, Denmark). The inlet air temperature was around $170{ }^{\circ} \mathrm{C}$, and the outlet temperature was around $90{ }^{\circ} \mathrm{C}$. Spray-dried solids were immediately placed in evacuated desiccators over $\mathrm{P}_{2} \mathrm{O}_{5}$ at room temperature. Each analysis was carried out within 3 months after spray-drying. 


\subsection{Powder characterisation}

\subsubsection{Determination of $\alpha$-lactose monohydrate content in spray-dried lactose/WPI mixtures}

The content of $\alpha$-lactose monohydrate in spray-dried lactose/WPI mixtures was

determined according to the method of Schuck and Dolivet (2002) based on the difference between total water, determined using a Karl Fischer Titration (Mettler Toledo International Inc., Im Langacher Greifensee, Switzerland), and unbound water, determined by weight loss following $6 \mathrm{~h}$ drying of $1 \mathrm{~g}$ powder at $87^{\circ} \mathrm{C}$. In this study, the content of $\alpha$-lactose monohydrate was used to represent the crystallinity of lactose/WPI mixtures. It was assumed that there was no bound water in amorphous lactose. Each analysis was carried out in triplicate.

\subsubsection{Light microscopy}

Lactose crystals were observed with a polarised light microscope fitted with a ProgRes ${ }^{\circledR}$ camera system (JENOPTIK I Optical Systems, Jena, Germany). The lactose/WPI mixtures were spread on slides and one drop of sunflower oil was used to blend with the samples. Coverslips were then placed on the sample, which was observed with a $10 \times$ objective. Images were acquired using an Olympus BX51 light microscope (Olympus Optical Co. Ltd., Tokyo, Japan) with polariser filters.

\subsubsection{Powder characteristics}

Protein content was determined using a FP 628 Nitrogen Determinator (LECO

Corporation, Lakeview Avenue, St. Joseph, MI, USA). Lactose content was determined using an Automatic Polarimeter (Autopol 1, Rudolph Research Analytical, Hackettstown, NJ, USA). Water content was determined using a HR83 Hologen Moisture Analyzer (Mettler Toledo International Inc., Im Langacher Greifensee, Switzerland). All chemical analysis of 
powders was carried out immediately after manufacture. Powder particle size distribution and specific surface area (SSA) were determined by laser light scattering using a Malver Mastersizer 3000 (Malvern Instruments, Worcestershire, UK).

\subsection{Water sorption and lactose crystallisation}

Water sorption for each powder was measured using the static gravimetric method and performed in triplicate. Approximately $1 \mathrm{~g}$ of spray-dried lactose/WPI mixtures was weighed into small glass vials $(25 \mathrm{~mL})$ and dried in a vacuum oven $(\mathrm{OV}-12$, Meline Industies, Inc., Mundelein, IL, USA) at $45{ }^{\circ} \mathrm{C}$ for $48 \mathrm{~h}$ to remove residual water. After drying, all samples were equilibrated for $240 \mathrm{~h}$ in evacuated desiccators over different saturated salt solutions. These saturated salt solutions were $\mathrm{LiCl}, \mathrm{CH}_{3} \mathrm{COOK}, \mathrm{MgCl}_{2}, \mathrm{~K}_{2} \mathrm{CO}_{3}, \mathrm{Mg}\left(\mathrm{NO}_{3}\right)_{2}$, and $\mathrm{NaNO}_{2}$, which gave relative humidity $(\mathrm{RH})$ of $11 \%, 23 \%, 33 \%, 44 \%, 54 \%$, and $65 \%$, respectively. All desiccators were placed in incubators set at $25{ }^{\circ} \mathrm{C}$ during equilibration. The was calculated.

The water sorption of lactose/WPI mixtures at $24 \mathrm{~h}$ was also monitored using a

Nagel-Str. 23, Ulm, Germany). The measurement cycles were started at 11\%, 23\%, 33\%, $44 \%, 54 \%$, and $65 \% \mathrm{RH}$, respectively, and ended at $11 \%, 23 \%, 33 \%, 44 \%, 54 \%$, and $65 \%$ water sorption results:

$$
\text { Sorption rate }=\text { Water content } / \text { time }\left(\% \mathrm{~h}^{-1}\right)
$$




\subsection{Differential scanning calorimetry}

(1)

$T_{g}$ (onset), and initial crystallisation temperatures, $\left(T_{i c}\right)$ of lactose/WPI mixtures were determined using a differential scanning calorimeter (DSC Q2000, TA Instruments, Crawley, UK). To determine the $T_{g}$, dairy powders $(1 \mathrm{~g})$ were transferred to glass vials and dried in the vacuum oven at $45{ }^{\circ} \mathrm{C}$ for $48 \mathrm{~h}$. The dehydrated powders were equilibrated in evacuated desiccators over $\mathrm{P}_{2} \mathrm{O}_{5}$ and saturated salt solutions of $\mathrm{LiCl}, \mathrm{CH}_{3} \mathrm{COOK}, \mathrm{MgCl}_{2}$, and $\mathrm{K}_{2} \mathrm{CO}_{3}$ for $168 \mathrm{~h}$. Then 10 to $15 \mathrm{mg}$ of equilibrated powders was transferred to Tzero pans (TA Instruments). The DSC pans were hermetically sealed with Tzero hermetic lids and samples were analysed. An empty pan was used as a reference. At the first scan, the samples were heated to at least $20{ }^{\circ} \mathrm{C}$ higher than the glass transition temperature region at $5{ }^{\circ} \mathrm{C} \mathrm{min}^{-1}$ and then cooled at $10{ }^{\circ} \mathrm{C} \min ^{-1}$ to $0{ }^{\circ} \mathrm{C}$; a second heating scan was then run to at least $100{ }^{\circ} \mathrm{C}$ higher than the glass transition temperature at $5^{\circ} \mathrm{C} \mathrm{min}^{-1}$. Anhydrous samples were scanned using pans with punctured lids to allow evaporation of residual water during the measurements (Silalai \& Roos, 2010). At the first scan, the samples were heated at $5{ }^{\circ} \mathrm{C} \mathrm{min}-1$ to $100{ }^{\circ} \mathrm{C}$ to evaporate residual water and then cooled at $10{ }^{\circ} \mathrm{C} \mathrm{min}^{-1}$ to below glass transition. A second heating scan was then performed on the anhydrous powders to far above the glass transition temperature at $5{ }^{\circ} \mathrm{C} \mathrm{min}^{-1}$. All measurements were carried out in duplicate. $T_{g}$ values were taken as the onset-point of the endothermic baseline shift. $T_{g}$ and $T_{i c}$ were determined using TA Universal analysis software, version 5.1.2 (TA Instruments).

\subsection{Dynamic mechanical analysis}

A Dynamic Mechanical Analyser (DMA Q800, TA Instruments) was used, in conjunction with a gas cooling accessory (GCA) tank, to determine the dynamic mechanical 
properties of lactose/WPI mixtures. A rectangular stainless steel powder holder was designed to generate a defined geometry to contain powder with inner dimensions of $60 \mathrm{~mm} \times 11 \mathrm{~mm}$ $\times 1 \mathrm{~mm}$. A pre-weighed mass of powder mixed with aluminium oxide calcined powder at the ratio 4:1 was evenly spread within this shallow container, and the upper lid was then placed onto the top surface of the powder (Mahlin, Wood, Hawkins, Mahey, \& Royall, 2009). As aluminium oxide calcined powder showed no influence on mechanical property results of dairy powders in the temperature range, it was added to protect dairy powder from sticking on the powder holder during the heating test. The sample holder was mounted in the instrument in a dual cantilever clamp during measurement. For anhydrous samples and samples equilibrated at $\mathrm{a}_{\mathrm{w}} 0.11$, the measurements were made at a heating rate of $2{ }^{\circ} \mathrm{C} \mathrm{min}-1$ from 0 to $150{ }^{\circ} \mathrm{C}$. For samples equilibrated at $\mathrm{a}_{\mathrm{w}} 0.23,0.33$ and 0.44 , the measurements were made at a heating rate of $2{ }^{\circ} \mathrm{C} \min ^{-1}$ from 0 to $120^{\circ} \mathrm{C}$. DMA was operated by a sinusoidal deformation applied to the powder sample holder at a fixed strain. The amplitude was $15 \mu \mathrm{m}$. During dynamic heating, the samples were analysed for storage modulus (E') and loss modulus (E') using single frequency $1 \mathrm{~Hz}$. Frequency of deformation (oscillating frequency) was changed in multiple frequencies of $0.5,1,3,5,10$, and $20 \mathrm{~Hz}$. The $\alpha$-relaxation times were determined directly from the frequencies $(f)$ using the relationship of Eq. (2) (Noel, Parker, \& Ring, 2000):

$$
\tau_{\alpha}=1 /(2 \pi f)
$$

The temperature dependence of $\alpha$-relaxation time was modelled using the VogelTamman-Fulcher (VTF) relationship of Eq. (3) (Angell, 2008; Silalai \& Roos, 2011a):

$$
\tau_{\alpha}=\mathrm{A} \exp \left[\mathrm{D} T_{0} /\left(T-T_{0}\right)\right]
$$

where $\mathrm{A}, \mathrm{D}$ and $T_{0}$ are constants.

\section{7. $\quad$ Statistical analysis}



were performed in duplicate, with all other analyses performed in triplicate. Results were expressed as mean \pm standard deviations (SD). One-way analysis of variance (ANOVA), followed by Tukey's test, was used to determine the significant differences between the mean values of each test (Microsoft Office Excel 2010, Microsoft, Inc., Redmond, WA, USA). A significance level of $P<0.05$ was used throughout the study.

\section{Results and discussion}

\subsection{Powder characterisation}

232

The characteristics of lactose/WPI mixtures are shown in Table 1. Crystalline lactose content increased as the pre-crystallisation time was increased (Table 1), yielding samples containing $1.0 \%$ (S1), $11.2 \%$ (S2), 29.2\% (S3) and 46.8\% (S4) crystalline lactose. The amount of crystalline lactose is defined as crystallinity of the samples in this study. The physical appearance of samples is shown in Fig. 1. It was obvious that the amount of crystalline lactose increased from S1 to S4, which further confirmed that the crystallinity of S1, S2, S3 and S4 was different. Lactose crystals were very hard and brittle and its particle shape was different from that of amorphous lactose, which might affect the physical properties and flow properties of dairy powders.

Protein and lactose contents for lactose/WPI mixtures were around 20\% and $80 \%$, respectively (Table 1). The particle size of S2, S3, and S4 was significantly larger than S1. However, there were only minor differences in the particle size between samples S2, S3, and S4. As specific surface area (SSA) values are typically inferred from particle size data, S1 
with the smallest particle size showed the largest SSA value. These results indicated that precrystallisation before spray drying could increase the particle size of dairy powders. But the amount of crystalline lactose showed only a minor effect on the particle size of powders.

These differences in particle size and SSA values of dairy powders can affect their physical properties and functionality.

\subsection{Water sorption and lactose crystallisation}

\subsubsection{Water sorption}

The experimental water content of lactose/WPI mixtures with different crystallinity equilibration at various $\mathrm{RH}$ is shown in Table 2. In lactose/WPI mixtures, the water may be sorbed by proteins, amorphous lactose, crystalline lactose, with some bound as the water of crystallisation 5\% of mass of crystals. The amount of water sorbed by S2 with $11.2 \%$ crystallinity was significantly higher $(P<0.05)$ than those of S1 (1.0\% crystallinity), S3 ( $29.2 \%$ crystallinity), and S4 (46.8\% crystallinity) at water activity range of aw $0.11-0.33$, while S3 sorbed the highest amount of water at aw 0.44 . S1, with the lowest crystallinity, did not sorb the highest amount of water at water activity range of $\mathrm{a}_{\mathrm{w}}$ 0.11- 0.44 , but did S1 sorb the highest amount of water at $\mathrm{a}_{\mathrm{w}} 0.54$ and 0.65 before showing loss of sorbed water. According to Bronlund and Paterson (2004), crystalline lactose sorbed very little water over the water activity range $\left(a_{w} 0-0.85\right)$. However, the presence of crystalline lactose in lactose/WPI mixtures did not show significant effect on their water sorption behaviour during equilibration (Table 2). It was assumed that the presence of WPI in dairy powders weakened the effect of crystalline lactose on water sorption behaviour of lactose/WPI mixtures.

Previous studies also indicated that water contents sorbed by lactose/WPI mixtures were determined by water sorption behaviour of non-crystalline lactose and protein (Fan \& Roos 2015). 

lactose crystallisation (Fig. 2). Loss of sorbed water occurred more rapidly at $a_{w} 0.65$ as compared with at $\mathrm{a}_{\mathrm{w}}$ 0.54, which was in agreement with the study of Haque and Roos (2004a).

Since loss of sorbed water does not occur in crystalline lactose, S2, S3, and S4 showed higher amount of stable water after lactose crystallisation than those of S1 without pre-crystallisation at $\mathrm{a}_{\mathrm{w}} 0.54$ and 0.65 (Fig. 2). These results indicated that the crystallinity showed minor influence on the water sorption behaviour of dairy powders containing protein at $\mathrm{a}_{\mathrm{w}} 0.11-$ 0.44. However, dairy powders with higher crystallinity showed higher stable water content after lactose crystallisation.

\subsubsection{Sorption rate}

Water sorption behaviour of lactose/WPI mixtures with different crystallinity was also measured using a Multisample Dynamic Moisture Sorption SPS11-10 $\mu$. Water sorption of lactose/WPI mixtures were near equilibrium within $24 \mathrm{~h}$ (raw data not shown). Using the water sorption results, sorption rates in the first hour of equilibration were calculated (Fig. 3).

The sorption rates of lactose/WPI mixtures increased with increasing storage relative humidity (Fig. 3A-F). The sorption rates of lactose/WPI mixtures decreased and then arrived at constant values (Fig. 3), and the final constant sorption rates of S1, S2, S3 and S4 were not significantly different at $\mathrm{a}_{\mathrm{w}} 0.11$ (Fig. 3A). The sorption rates of $\mathrm{S} 2$, with $11.2 \%$ crystallinity, were higher than those of $\mathrm{S} 1, \mathrm{~S} 3$, and $\mathrm{S} 4$ at $\mathrm{a}_{\mathrm{w}} 0.23-0.65$. In addition, the initial sorption rates of lactose/WPI mixtures were divided into two groups, higher initial sorption rate group for S1 and S2 with lower crystallinity, and lower initial sorption rate group for S3 and S4 with higher crystallinity (Fig. 3). It was obvious that the difference between two groups increased with increasing storage relative humidity. Therefore, the crystallinity affected the initial 
sorption rate of the lactose/WPI mixtures significantly; samples with higher crystallinity showed lower sorption rates.

\subsection{Glass transition}

The $T_{g}$ and $T_{i c}$ values for anhydrous and equilibrated lactose/WPI mixtures are shown in Table 3. It was obvious that the $T_{g}$ values of lactose/WPI mixtures decreased with increasing water content, which showed typical water plasticisation of dairy powders containing lactose (Haque et al., 2006; Jouppila et al., 1997; Potes et al., 2012). There was no significant difference in the $T_{g}$ values of lactose/WPI mixtures with different levels of crystallinity at the same water activities. Therefore, the $T_{g}$ values of lactose/WPI mixtures with different amount of crystalline lactose was primarily dependent on the amorphous lactose, which was in agreement with previous studies. According to previous studies (Fan \& Roos, 2015; Potes et al., 2012; Silalai \& Roos, 2010), lactose-protein systems showed phase separation and their $T_{g}$ values were dependent on amorphous lactose. The $T_{g}$ values of lactose/WPI mixtures in this study were higher than those reported by Haque and Roos (2004b) and Fan and Roos (2015) for lactose/WPI mixtures at corresponding water activities. As water content significantly affected $T_{g}$ values of dairy powders, the differences in the $T_{g}$ values between our study and other studies were probably a result of different water contents with equilibration at $a_{w} 0.11-0.44$. Haque and Roos (2004a) have indicated that drying methods, storage time, and storage temperature could result in the differences in final water content of lactose/protein mixtures. In addition, the $T_{i c}$ values of lactose/WPI mixtures also decreased with increasing water content (Table 3). Since lactose crystallisation could be delayed by the presence of protein, the $T_{i c}$ values of lactose/WPI mixtures was higher than that of pure lactose (Haque \& Roos, 2004b; Zhou \& Roos, 2012). Lactose/WPI mixtures with 
different amount of crystalline lactose showed similar $T_{i c}$ values in the range of $\mathrm{a}_{\mathrm{w}} 0.11-0.44$. Therefore, the amount of crystalline lactose showed no significant influence on the $T_{i c}$ values of the lactose/WPI mixtures.

\subsection{Mechanical properties}

\subsubsection{Modulus and stiffness}

The physical properties of amorphous materials often change around the glass transition temperatures, which may result in an $\alpha$-relaxation (Roudaut, Simatos, Champion, Contreras-Lopez \& Le Meste, 2004; Silalai \& Roos, 2011a,b). The mechanical properties of lactose/WPI mixtures with different amount of crystalline lactose were measured by DMA. A loss of water occurred during dynamic measurements for dairy powders with lower water activities $\left(\mathrm{a}_{\mathrm{w}}<0.23\right)$, which was also reported by Silalai and Roos (2011b). Moreover, lactose/WPI mixtures showed lactose crystallisation during storage at $\mathrm{a}_{\mathrm{w}} 0.54$ and 0.65 . Therefore, the results of mechanical properties of lactose/WPI mixtures at $a_{w} 0.11,0.54$ and 0.65 are not shown. Mechanical $\alpha$-relaxation of lactose/WPI mixtures occurred above $T_{g}$ and was observed from a sharp decrease in their storage modulus and a peak in their loss modulus (Fig. 4). The storage modulus shows the amount of energy that the material stores (Edward, Kirui, Omolo, Ngumbu \& Odhiambo, 2014). Furthermore, the magnitudes of storage modulus and loss modulus changes are relative to molecular mobility (Roudaut et al., 2004; Silalai \& Roos, 2010, 2011b). As can be seen from Fig.4 A1, B1, and C1, samples S4, with the highest crystallinity, showed higher storage modulus than samples S1, S2, and S3 at the glassy state at $\mathrm{a}_{\mathrm{w}} 0.23-0.44$. Additionally, the difference in storage modulus of lactose/WPI mixtures increased with increasing storage RH (Fig. 4 A1, B1 and C1). At the glassy state, the storage modulus of lactose/WPI mixtures with lower crystallinity (S1 and S2) decreased 
significantly from $\mathrm{a}_{\mathrm{w}} 0.33$ to $\mathrm{a}_{\mathrm{w}} 0.44$ (from 208,295 MPa to 135,679 MPa for S1; from 214,528 MPa to 110,495 MPa for S2) (Fig. 4 B1 and C1). The storage modulus of S4 with $46.8 \%$ crystallinity showed the smallest change at the glassy state with increasing water content $\left(222,785 \mathrm{MPa}\right.$ at $\mathrm{a}_{\mathrm{w}} 0.33 ; 214,190 \mathrm{MPa}$ at $\left.\mathrm{a}_{\mathrm{w}} 0.44\right)$. These results indicated that the addition of crystalline lactose could maintain the stiffness of dairy powders when water content is increased. This might be due to the different molecular mobility and free volume of amorphous and crystalline state lactose. According to Kilburn et al. (2004), the effect of water plasticisation in carbohydrates solids is related to hydrogen bond formation and disruption, and also involves to the changes in free volume. Unlike amorphous structure, the crystalline state has molecules well arranged, which is in the favourable low energy state. Water plasticisation showed no significant effect on molecular mobility of crystalline lactose, and only exhibited a minor effect on the storage modulus of dairy powders with higher crystallinity. At the glass transition region, the storage modulus of lactose/WPI mixtures decreased significantly at $a_{w} 0.23,0.33$ and 0.44 as a result of increasing molecular mobility (Fig. 4 A1, B1 and C1). A greater change in the storage modulus was experienced with lactose/WPI mixtures at $\mathrm{a}_{\mathrm{w}} 0.33$ and 0.44 compared with at $\mathrm{a}_{\mathrm{w}} 0.23$, which indicated that lactose/WPI mixtures with higher water content showed higher molecular mobility at the glass transition region. Therefore, the magnitude of the storage modulus changes of lactose/WPI mixtures were affected by the amount of crystalline lactose and water. Dairy powders with higher crystallinity showed lower molecular mobility with increasing temperature.

Stiffness of materials refers to the ability to carry stress without changing dimension (Ebewele, 2000). For the measurement of unconstrained uniaxial tension or compression, Young's modulus can be used as a measure of the stiffness of a material. In this study, the change of storage modulus could reflect the change of stiffness of lactose/WPI mixtures. The 
changes of stiffness for lactose/WPI mixtures were directly related to the storage modulus when temperature increased from 0 to $120^{\circ} \mathrm{C}$ at $1 \mathrm{~Hz}$ (the stiffness results were not shown). $\mathrm{S} 4$ with the highest crystallinity gave the largest storage modulus at $\mathrm{a}_{\mathrm{w}} 0.23,0.33$ and 0.44 (Fig. 4 A1, B1 and C1), which meant S4 had the highest stiffness at $\mathrm{a}_{\mathrm{w}} 0.23$ to 0.44 . However, S1 and S2 with lower crystallinity showed lower stiffness at $\mathrm{a}_{\mathrm{w}} 0.33$ and 0.44 . These results indicated that dairy powders with higher amount of crystalline lactose had higher stiffness, which might be due to the physical properties of crystalline lactose. As crystallinity is the result of a highly ordered arrangement of the lactose molecules, lactose crystals are very hard and stiff.

The changes of loss modulus for lactose/WPI mixtures with different crystallinity were also determined using the DMA. The loss modulus, E”, of lactose/WPI mixtures showed minor changes at the glassy state and the rubbery state, while they increased dramatically and arrived at the peak values in the glass transition region (Fig. 4 A2, B2 and C2). This result could be explained from the point of mechanical internal friction (Guo, Feng, Wang, Hu, \& Zhang, 2013). According to Guo et al. (2013), the chain segment motion of lactose and proteins molecules is in a frozen state when in the glassy state, and is in a free moving state when in the rubbery state. The chain segment motion changes from a frozen state to a free moving state during the glass transition region. This change of motion leads to large internal loss. The internal friction loss approaches maximum as the temperature reaches glass transition temperature, which is reflected from the peak of loss modulus. Since the physical state of amorphous powders is strongly affected by the concentration of water, the peak values of loss modulus for lactose/WPI mixtures increased as water content was increased (Fig. 4 A2, B2, and C2). Moreover, the loss modulus of lactose/WPI mixtures in the glassy state also increased with increasing water content, especially for S1 with the lowest crystallinity (3211 MPa at $\mathrm{a}_{\mathrm{w}} 0.33 ; 11,442 \mathrm{MPa}$ at $\left.\mathrm{a}_{\mathrm{w}} 0.44\right)$. Since the magnitude of loss 
modulus changes is also related to the molecular mobility, dairy powders with lower crystallinity showed higher molecular mobility as water content was increased.

\subsubsection{Mechanical structural relaxation}

In this study, the $\alpha$-relaxation temperatures, $T_{\alpha}$, were taken from the temperatures of loss modulus peak values at $1 \mathrm{~Hz} . T_{\alpha}$ values of dairy powders shifted to lower temperatures with increasing water content (Table 3), which was in agreement with previous studies ( $\mathrm{Li}$, Roos, \& Miao, 2016; Potes et al., 2012; Silalai \& Roos, 2011b). Lactose/WPI mixtures with different crystallinity showed similar $T_{\alpha}$ values at $\mathrm{a}_{\mathrm{w}} 0$ and 0.11 , while $\mathrm{S} 1$ with the lowest amount of crystalline lactose showed the highest $T_{\alpha}$ values at $\mathrm{a}_{\mathrm{w}} 0.23-0.44$. Furthermore, the mechanical $\alpha$-relaxations for lactose/WPI mixtures at $\mathrm{a}_{\mathrm{w}} 0.23,0.33$, and 0.44 were determined by DMA using multi-frequency mode. The magnitude of mechanical $\alpha$ relaxations for lactose/WPI mixtures decreased when frequency was increased (data not shown).

Many studies have indicated that the Vogel-Tammann-Fulcher (VTF) relationship can be used to describe the temperature dependence of relaxation times for amorphous materials at temperatures above glass transition (Angell, 1995, 2008; Angell, Ngai, McKenna, McMillan, \& Martin, 2000; Potes et al., 2012; Silalai \& Roos, 2011b). The VTF plots indicated that the $T_{\alpha}$ values of lactose/WPI mixtures at various frequencies were at higher temperatures with increasing frequency (Fig. 5). Moreover, lower $T-T_{g}$ values were shown by $\mathrm{S} 1$ for the corresponding relaxation at $\mathrm{a}_{\mathrm{w}}$ 0.23-0.44, which meant $\alpha$-relaxation of S1 occurred at lower temperatures above $T_{g}$ values than those of S2, S3, and S4. Comparing the VTF plots at $\mathrm{a}_{\mathrm{w}} 0.23$ and 0.33 (Fig. $5 \mathrm{~A}$ and $\mathrm{B}$ ), the $\alpha$-relaxations of lactose/WPI mixtures occurred at higher $T-T_{g}$ values as water content was increased. Then the $T-T_{g}$ values of S1 and S2 decreased when $\mathrm{a}_{\mathrm{w}}$ was increased from 0.33 to 0.44 (Fig. $5 \mathrm{~B}$ and C), while those of S3 and 
S4 showed only minor changes. According to Liu et al. (2006), the viscosity and molecular mobility of S1 and S2 with lower crystallinity might have strong temperature dependence. Thus, they exhibit larger changes on relaxation time in the vicinity of the glass transition than dairy powders with higher crystallinity. Therefore, water plasticisation had a stronger effect on the structural relaxation of dairy powders with lower crystallinity.

\section{Conclusions}

As crystalline lactose and amorphous lactose have different molecular arrangement, they show different behaviour in physical properties and functionality. Lactose/WPI mixtures with different amount of crystalline lactose were prepared by pre-crystallisation. Particle size of dairy powders with $11.2 \%, 29.2 \%$, and $46.8 \%$ crystallinity was significantly $(P<0.05)$ larger than that of dairy powder with $1.0 \%$ crystallinity. Since physical properties, flowability and functionality of dairy powders are highly dependent on the particle size of powders, precrystallisation could have a significant impact on the final properties of dairy powers. The presence of less than $46.8 \%$ crystalline lactose in dairy powders showed only a minor effect on water sorption behaviour of dairy powder at $\mathrm{a}_{\mathrm{w}} 0.11-0.44$. Dairy powders with higher crystallinity showed higher stable water content after lactose crystallisation. Furthermore, dairy powders with lower amount of crystalline lactose showed higher sorption rates at the beginning of water sorption. Increasing the amount of crystalline lactose in dairy powders did not have significant influence on the $T_{g}$ and $T_{i c}$ values. The mechanical property study showed that lactose/WPI mixtures with higher amount of crystalline lactose had higher stiffness, and the addition of crystalline lactose could maintain the stiffness of dairy powders when water content is increased. Water plasticisation had a stronger effect on the structural relaxation of dairy powders with lower amount of crystalline lactose. Since pre-crystallisation 
445 of lactose is widely used in the production of dairy powders, the findings of this study could 446 be very useful in the dairy industry.

447

\section{Acknowledgement}

This study was supported financially by the Food Institutional Research Measure

(FIRM) of the Department of Agriculture, Food and Marine, Ireland, under the project 11-F001 entitled 'Formulation and Design for Food Structure and stability'.

\section{References}

Aguilar, C. A., \& Ziegler, G. R. (1994). Physical and microscopic characterization of dry whole milk with altered lactose content. 2. Effect of lactose crystallization. Journal of Dairy Science, 77, 1198-1204.

Angell, C. A. (1995). Formation of glasses from liquids and biopolymers. Science, 267, 19241935.

Angell, C. A. (2008). Glass formation and glass transition in supercooled liquids, with insights from study of related phenomena in crystals. Journal of Non-crystalline Solids, 354, 4703-4712.

Angell, C. A., Ngai, K. L., McKenna, G. B., McMillan, P. F., \& Martin, S. W. (2000). Relaxation in glassforming liquids and amorphous solids. Journal of Applied Physics, $88,3113-3157$.

Arellano, M. A. P., Aguilera, J. M., \& Bouchon, P. (2004). Development of a digital videomicroscopy technique to study lactose crystallisation kinetics in situ. Carbohydrate Research, 339, 2721-2730. 
Bandyopadhyay, P., Das, H., \& Sharma, G. (1987). Moisture adsorption characteristics of casein, lactosem, skim milk and chhana powder. Journal of Food Science and Technology, 24, 6-11.

Berlin, E., Anderson, B., \& Pallansch, M. (1968a). Water vapor sorption properties of various dried milks and wheys. Journal of Dairy Science, 51, 1339-1344.

Berlin, E., Anderson, B., \& Pallansch, M. (1968b). Comparison of water vapor sorption by milk powder components. Journal of Dairy Science, 51, 1912-1915.

Berlin, E., Anderson, B., \& Pallansch, M. (1970). Effect of temperature on water vapor sorption by dries milk powders. Journal of Dairy Science, 53, 146-149.

Bronlund, J., \& Paterson, T. (2004). Moisture sorption isotherms for crystalline, amorphous and predominantly crystalline lactose powders. International Dairy Journal, 14, 247254.

Buckton, G., \& Darcy, P. (1996). Water mobility in amorphous lactose below and close to the glass transition temperature. International Journal of Pharmaceutics, 136, 141-146.

Ebewele, R. O. (2000). Polymer science and technology. Boca Raton, FL, USA: CRC Press LLC.

Edward, T. L., Kirui, M. S., Omolo, J. O., Ngumbu, R. G., \& Odhiambo, P. M. (2014). Effect of ultraviolet-A (UV-A) and ultraviolet-C (UV-C) light on mechanical properties of oyster mushrooms during growth. Journal of Biophysics, 2014.

Fan, F., \& Roos, Y. H. (2015). X-ray diffraction analysis of lactose crystallization in freezedried lactose-whey protein systems. Journal of Food Research International, 67, 1-11.

Foster, K., Bronlund, J., \& Paterson A. (2005). The prediction of moisture sorption isotherms for dairy powders. International Dairy Journal, 15, 411-418. 
Guo, Z.-S., Feng, J., Wang, H., Hu, H., \& Zhang, J. (2013). A new temperature-dependent modulus model of glass/epoxy composite at elevated temperatures. Journal of Composite Materials, 47, 3303-3310.

Haque, M.K., \& Roos, Y. H. (2004a). Water sorption and plasticization behavior of spraydried lactose/protein mixtures. Journal of Food Science, 69, E384-E391.

Haque, M. K., \& Roos, Y. H. (2004b). Water plasticization and crystallization of lactose in spray-dried lactose/protein mixtures. Journal of Food Science, 69, FEP23-FEP29.

Haque, M. K., \& Roos, Y. H. (2005). Crystallization and X-ray diffraction of spray-dried and freeze-dried amorphous lactose. Carbohydrate Research, 340, 293-301.

Haque, M. K., \& Roos, Y. H. (2006). Differences in the physical state and thermal behavior of spray-dried and freeze-dried lactose and lactose/protein mixtures. Innovative Food Science and Emerging Technologies, 7, 62-73.

Haque, M. K., Kawai, K., \& Suzuki, T. (2006). Glass transition and enthalpy relaxation of amorphous lactose glass. Carbohydrate Research, 341, 1884-1889.

Hancock, B. C., Shamblin, S. L., \& Zografi, G. (1995). Molecular mobility of amorphous pharmaceutical solids below their glass transition temperatures. Pharmaceutical Research, 12, 799-806.

Hermansson, A. (1977). Functional properties of proteins for foods-water vapour sorption. International Journal of Food Science and Technology, 12, 177-187.

Hogan, S. E., \& Buckton, G. (2001). Water sorption/desorption—near IR and calorimetric study of crystalline and amorphous raffinose. International Journal of Pharmaceutics, 227, 57-69.

Ibach, A., \& Kind, M. (2007). Crystallization kinetics of amorphous lactose, whey-permeate and whey powders. Carbohydrate Research, 342, 1357-1365. 
Jones, D.S. (1999). Dynamic mechanical analysis of polymeric systems of pharmaceutical and biomedical significance. International Journal of Pharmaceutics, 179, 167-178.

Jouppila, K., Kansikas, J., \& Roos, Y. H. (1997). Glass transition, water plasticization, and lactose crystallization in skim milk powder. Journal of Dairy Science, 80, 3152-3160.

Kaminaski, W., \& Al-Bezweni, M. (1994). Calculation of water sorption isotherms for multicomponent protein-containing mixtures. International Journal of Food Science \& Technology, 29, 129-136.

Kasapis, S. (2001). Advanced topics in the application of the WLF/free volume theory to high sugar/biopolymer mixture: a review. Food Hydrocolloids, 15, 631-641.

Kilburn, D., Claude, J., Mezzenga, R., Dlubek, G., Alam, A., \& Ubbink, J. (2004). Water in glassy carbohydrates: Opening it up at the nanolevel. Journal of Physical Chemistry B, $108,12436-12441$.

Li, R., Roos, Y. H., \& Miao, S. (2016). The effect of water plasticization and lactose content on flow properties of dairy model solids. Journal of Food Engineering, 170, 50-57.

Liu, Y., Bhandari, B., \& Zhou, W. (2006). Glass transition and enthalpy relaxation of amorphous food saccharides: a review. Journal of Agricultural and Food Chemistry, $54,5701-5717$.

Mahlin, D., Wood, J., Hawkins, N., Mahey, J., \& Royall, P. G. (2009). A novel powder sample holder for the determination of glass transition temperatures by DMA. International Journal of Pharmaceutics, 371, 120-125.

McSweeney, P., \& Fox, P. F. (2009). Advanced dairy chemistry. Vol. 3. Lactose, water, salts and minor constituents. New York, NY, USA: Springer-Verlag.

Miao, S., \& Roos, Y. H. (2004). Comparison of nonenzymatic browning kinetics in spraydried and freeze-dried carbohydrate-based food model systems. Journal of Food Science, 69, 322-331. 
Noel, T. R., Parker, R., \& Ring, S. G. (2000). Effect of molecular structure and water content on the dielectric relaxation behaviour of amorphous low molecular weight carbohydrates above and below their glass transition. Carbohydrate Research, 329, $839-845$.

Potes, N., Kerry, J. P., \& Roos, Y. H. (2012). Additivity of water sorption, alpha-relaxations and crystallization inhibition in lactose-maltodextrin systems. Carbohydrate Polymers, 89, 1050-1059.

Roos, Y. H., \& Karel, M. (1991). Phase transitions of mixtures of amorphous polysaccharides and sugars. Biotechnology Progress, 7, 49-53.

Roos, Y. H., Jouppila, K., \& Söderholm, E. (1999). Crystallization of amorphous food components and polymers. Water Management in the Design and Distribution of Quality Foods: ISOPOW, 7, 429-451.

Roudaut, G., Simatos, D., Champion, D., Contreras-Lopez, E., \& Le Meste, M. (2004). Molecular mobility around the glass transition temperature: a mini review. Innovative Food Science and Emerging Technologies, 5, 127-134.

Royall, P. G., Huang, C., Tang, S. J., Duncan, J., Van-de-Velde, G., \& Brown, M. B. (2005). The development of DMA for the detection of amorphous content in the pharmaceutical powdered materials. International Journal of Pharmaceutics, 301, $181-191$.

Schuck, P., \& Dolivet, A. (2002). Lactose crystallization: determination of $\alpha$-lactose monohydrate in spray-dried dairy products. Lait, 82, 413-421.

Shrestha, A. K., Howes, T., Adhikari, B. P., \& Bhandari, B. R. (2007). Water sorption and glass transition properties of spray dried lactose hydrolysed skim milk powder. $L W T$ Food Science and Technology, 40, 1593-1600. 
566 Silalai, N., \& Roos, Y. H. (2010). Roles of water and solids composition in the control of 567 glass transition and stickiness of milk powders. Journal of Food Science, 75, E285$568 \quad$ E296.

569 Silalai, N., \& Roos, Y. H. (2011a). Coupling of dielectric and mechanical relaxations with 570 glass transition and stickiness of milk solids. Journal of Food Engineering, 104, 445571454.

572 Silalai, N., \& Roos, Y. H. (2011b). Mechanical relaxation times as indicators of stickiness in skim milk-maltodextrin solids systems. Journal of Food Engineering, 106, 306-317.

574 Zhou, Y., \& Roos, Y. H. (2012). Stability and plasticizing and crystallisation effects of vitamins in amorphous sugar systems. Journal of Agricultural and Food Chemistry, $60,1075-1083$. 


\section{$1 \quad$ Table 1}

2 Powder characteristics of lactose/WPI (4:1) mixtures. ${ }^{\text {a }}$

\begin{tabular}{lllllll}
\hline System & $\begin{array}{l}\text { Crystallinity } \\
(\%)\end{array}$ & $\begin{array}{l}\text { Protein } \\
\text { content }(\%)\end{array}$ & $\begin{array}{l}\text { Lactose } \\
\text { content }(\%)\end{array}$ & $\begin{array}{l}\text { Water } \\
\text { content }(\%)\end{array}$ & $\begin{array}{l}d_{50} \\
(\mu \mathrm{m})\end{array}$ & $\begin{array}{l}\text { Specific surface } \\
\text { area }\left(\mathrm{m}^{2} \mathrm{~kg}^{-1}\right)\end{array}$ \\
\hline S1 & $1.0 \pm 0.58$ & $19.94 \pm 0.07$ & $78.91 \pm 0.02$ & $2.47 \pm 0.04$ & $22.85 \pm 0.25^{\mathrm{c}}$ & $714.75 \pm 7.45^{\mathrm{a}}$ \\
S2 & $11.2 \pm 0.97$ & $19.55 \pm 0.04$ & $79.03 \pm 0.11$ & $2.93 \pm 0.16$ & $25.35 \pm 0.05^{\mathrm{a}}$ & $629.95 \pm 0.85^{\mathrm{c}}$ \\
S3 & $29.2 \pm 0.92$ & $19.45 \pm 0.02$ & $78.99 \pm 0.06$ & $2.45 \pm 0.09$ & $25.20 \pm 1.20^{\mathrm{ab}}$ & $682.10 \pm 9.30^{\mathrm{b}}$ \\
S4 & $46.8 \pm 1.11$ & $19.66 \pm 0.02$ & $79.45 \pm 0.09$ & $2.53 \pm 0.15$ & $23.85 \pm 0.05^{\mathrm{b}}$ & $695.05 \pm 1.05^{\mathrm{b}}$ \\
\hline
\end{tabular}

$4{ }^{\mathrm{a}}$ Values are means \pm standard deviation ( $\mathrm{n}=2$ for protein content; for the other values, $\mathrm{n}=3$ );

5 values within columns with different superscript letters are significantly different at $P<0.05$.

6

7

8

9

10

11

12

13

14

15

16

17

18

19

20

21

22

23 
Table 2

25

26

27

28

29

30

31

32

33

34

35

36

37

38

39

40

41

42

43

44

45

Water content of lactose/WPI (4:1) mixtures with 1.0\% (S1), 11.2\% (S2), 29.2\% (S3) and $46.8 \%$ (S4) crystallinity after equilibration at $\mathrm{a}_{\mathrm{w}} 0.11-0.65$ at $25^{\circ} \mathrm{C}$ for $240 \mathrm{~h}$. ${ }^{\mathrm{a}}$

\begin{tabular}{lllll}
\hline $\mathrm{a}_{\mathrm{w}}$ & $\mathrm{S} 1$ & $\mathrm{~S} 2$ & $\mathrm{~S} 3$ & $\mathrm{~S} 4$ \\
\hline 0.11 & $2.48 \pm 0.00^{\mathrm{b}}$ & $2.77 \pm 0.03^{\mathrm{a}}$ & $2.54 \pm 0.09^{\mathrm{b}}$ & $2.45 \pm 0.03^{\mathrm{b}}$ \\
0.23 & $4.13 \pm 0.11^{\mathrm{b}}$ & $4.33 \pm 0.05^{\mathrm{a}}$ & $4.26 \pm 0.04^{\mathrm{a}}$ & $4.00 \pm 0.04^{\mathrm{c}}$ \\
0.33 & $5.94 \pm 0.11^{\mathrm{b}}$ & $6.05 \pm 0.05^{\mathrm{a}}$ & $6.04 \pm 0.07^{\mathrm{a}}$ & $5.71 \pm 0.05^{\mathrm{c}}$ \\
0.44 & $8.69 \pm 0.07^{\mathrm{b}}$ & $8.52 \pm 0.02^{\mathrm{c}}$ & $8.76 \pm 0.11^{\mathrm{a}}$ & $8.43 \pm 0.05^{\mathrm{d}}$ \\
0.54 & $5.68 \pm 0.04^{\mathrm{b}}$ & $6.78 \pm 0.32^{\mathrm{a}}$ & $6.85 \pm 0.07^{\mathrm{a}}$ & $6.90 \pm 0.06^{\mathrm{a}}$ \\
0.65 & $7.17 \pm 0.08^{\mathrm{c}}$ & $7.78 \pm 0.13^{\mathrm{b}}$ & $7.85 \pm 0.06^{\mathrm{b}}$ & $8.51 \pm 0.05^{\mathrm{a}}$ \\
\hline
\end{tabular}

${ }^{\mathrm{a}}$ Values (g $100 \mathrm{~g}^{-1}$ of dry solids) are means \pm standard deviation $(\mathrm{n}=3)$; values within columns with different superscript letters are significantly different at $P<0.05$. 
Table 3

47 Glass transition temperature $\left(T_{g}\right)$, initial crystallisation temperature $\left(T_{i c}\right)$, and $\alpha$-relaxation 48 temperature $\left(T_{\alpha}\right)$ of lactose/WPI (4:1) mixtures with $1.0 \%(\mathrm{~S} 1), 11.2 \%(\mathrm{~S} 2), 29.2 \%(\mathrm{~S} 3)$ and $4946.8 \%$ (S4) crystallinity equilibrated at $\mathrm{a}_{\mathrm{w}} 0-0.44$ at $25^{\circ} \mathrm{C}$ for $168 \mathrm{~h}^{\text {a }}$

\begin{tabular}{|c|c|c|c|c|c|c|}
\hline \multirow[t]{2}{*}{$\overline{\text { Systems }}$} & & \multicolumn{5}{|c|}{ Water activity $\left(\mathrm{a}_{\mathrm{w}}\right)$} \\
\hline & & 0 & 0.11 & 0.23 & 0.33 & 0.44 \\
\hline \multirow[t]{3}{*}{$\mathrm{S} 1$} & $T_{g}$ & $105 \pm 0.5$ & $71 \pm 0.0$ & $58 \pm 0.5$ & $40 \pm 0.0$ & $21 \pm 0.5$ \\
\hline & $T_{i c}$ & / & $127 \pm 1.0$ & $115 \pm 0.5$ & $94 \pm 0.5$ & $72 \pm 0.0$ \\
\hline & $T_{\alpha}$ & $126.5 \pm 0.4$ & $126.6 \pm 0.4$ & $80.0 \pm 0.3$ & $70.6 \pm 0.9$ & $44.4 \pm 1.1$ \\
\hline \multirow[t]{3}{*}{$\mathrm{S} 2$} & $T_{g}$ & $105 \pm 0.0$ & $70 \pm 0.0$ & $58 \pm 0.5$ & $40 \pm 0.5$ & $22 \pm 0.0$ \\
\hline & $T_{i c}$ & / & $125 \pm 0.5$ & $112 \pm 0.0$ & $92 \pm 0.5$ & $73 \pm 0.5$ \\
\hline & $T_{\alpha}$ & $125.8 \pm 0.1$ & $125.1 \pm 0.3$ & $77.8 \pm 0.7$ & $66.4 \pm 0.9$ & $37.4 \pm 0.9$ \\
\hline \multirow[t]{3}{*}{ S3 } & $T_{g}$ & $104 \pm 0.5$ & $70 \pm 0.0$ & $58 \pm 1.0$ & $39 \pm 0.0$ & $21 \pm 0.0$ \\
\hline & $T_{i c}$ & I & $126 \pm 1.0$ & $114 \pm 0.5$ & $93 \pm 0.0$ & $73 \pm 0.5$ \\
\hline & $T_{\alpha}$ & $127.0 \pm 0.3$ & $127.0 \pm 0.3$ & $78.9 \pm 0.3$ & $61.0 \pm 0.6$ & $38.0 \pm 0.9$ \\
\hline \multirow[t]{3}{*}{ S4 } & $T_{g}$ & $105 \pm 0.0$ & $70 \pm 0.5$ & $58 \pm 0.0$ & $38 \pm 0.5$ & $21 \pm 0.5$ \\
\hline & $T_{i c}^{\circ}$ & I & $127 \pm 0.5$ & $113 \pm 0.5$ & $93 \pm 0.5$ & $72 \pm 0.0$ \\
\hline & $T_{\alpha}$ & $127.0 \pm 0.4$ & $126.3 \pm 0.2$ & $77.9 \pm 0.5$ & $62.0 \pm 0.8$ & $41.0 \pm 0.9$ \\
\hline
\end{tabular}

50

$51{ }^{a}$ Values are mean \pm standard deviation $(n=2)$. 


\section{Figure legends}

Fig. 1. Images obtained by polarised light microscope for lactose/WPI (4:1) mixtures with $1.0 \%(\boldsymbol{\square}, \mathrm{S} 1), 11.2 \%(\boldsymbol{\bullet}, \mathrm{S} 2), 29.2 \%(\boldsymbol{\Delta}, \mathrm{S} 3)$ and $46.8 \%(\boldsymbol{\nabla}, \mathrm{S} 4)$ crystallinity.

Fig. 2. Lactose crystallisation at (A) $a_{w} 0.54$ and (B) $a_{w} 0.65$ at $25^{\circ} \mathrm{C}$ of lactose/WPI (4:1) mixtures with $1.0 \%(\mathrm{~S} 1), 11.2 \%(\mathrm{~S} 2), 29.2 \%(\mathrm{~S} 3)$ and $46.8 \%$ (S4) crystallinity.

Fig. 3. Sorption rate of lactose/WPI (4:1) mixtures with $1.0 \%$ (solid line, S1), $11.2 \%$ (dashed line, S2), 29.2\% (dotted line, S3) and 46.8\% (dot-dash line, S4) crystallinity during equilibration for $24 \mathrm{~h}$ at $25^{\circ} \mathrm{C}$ at $\mathrm{a}_{\mathrm{w}}$ of: $\mathrm{A}, 0.11 ; \mathrm{B}, 0.23 ; \mathrm{C}, 0.33 ; \mathrm{D}, 0.44$ : E, 0.54; F, 0.65.

Fig. 4. Storage modulus (A, C, E) and loss modulus (B, D, F) of lactose/WPI (4:1) mixtures with $1.0 \%$ (dashed line, S1), 11.2\% (dotted line, S2), 29.2\% (dash-dot line, S3) and 46.8\% (dash-dot-dot line, S4) crystallinity during equilibration at $25^{\circ} \mathrm{C}$ for $168 \mathrm{~h}$ at $\mathrm{a}_{\mathrm{w}}$ of: $\mathrm{A}$ and $\mathrm{B}$, 0.23; C and D, 0.33; E and F, 0.44.

Fig. 5. Plots of $\ln$ relaxation time against temperature difference $1 /\left(T-T_{g}\right)$ for lactose/WPI (4:1) mixtures with $1.0 \%(\boldsymbol{\square}, \mathrm{S} 1), 11.2 \%(\boldsymbol{\bullet}, \mathrm{S} 2), 29.2 \%(\boldsymbol{\Delta}, \mathrm{S} 3)$ and $46.8 \%(\boldsymbol{\nabla}, \mathrm{S} 4)$ crystallinity during equilibration at $25^{\circ} \mathrm{C}$ for $168 \mathrm{~h}$ at $\mathrm{a}_{\mathrm{w}}$ of: $\mathrm{A}, 0.23 ; \mathrm{B}, 0.33 ; \mathrm{C}, 0.44$. 
S1

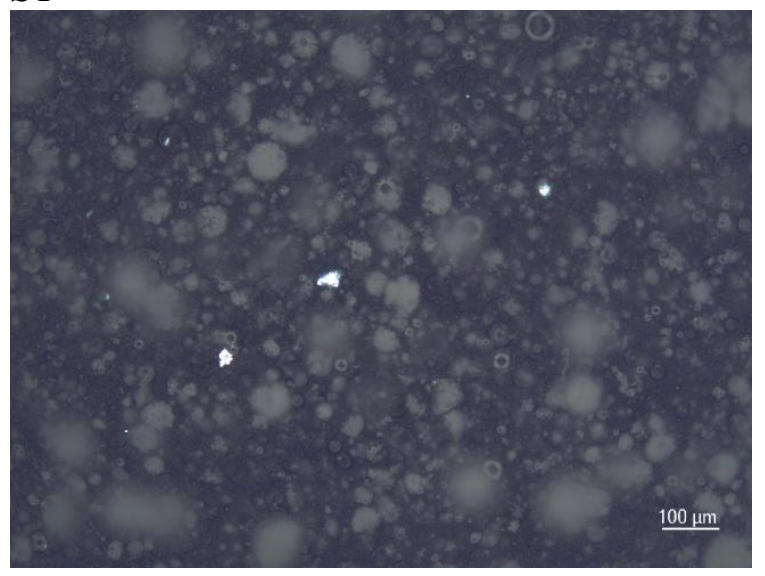

S3

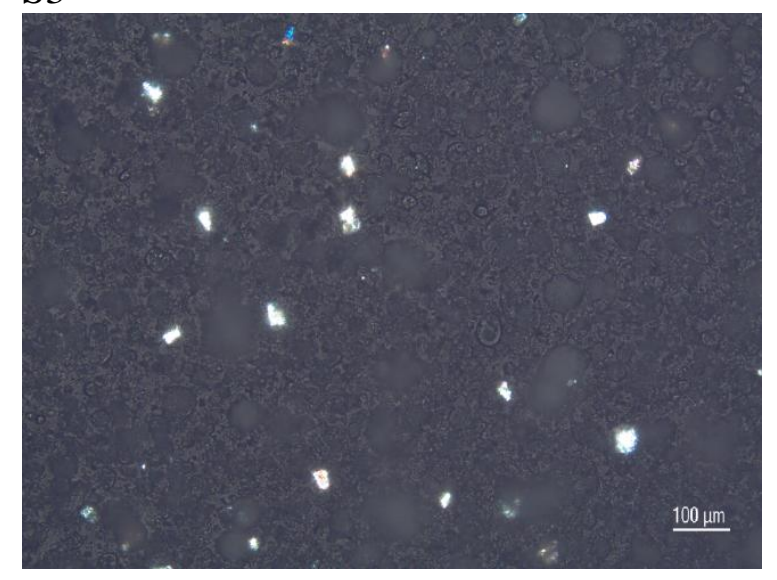

S2

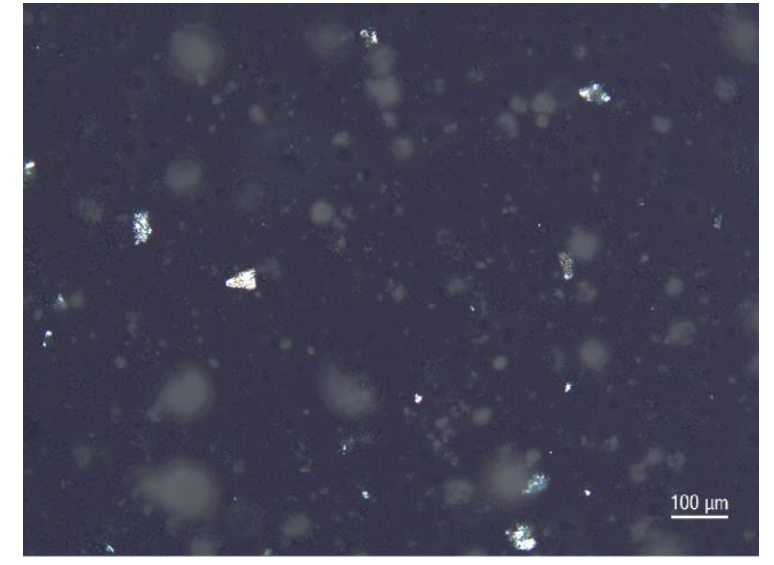

S4

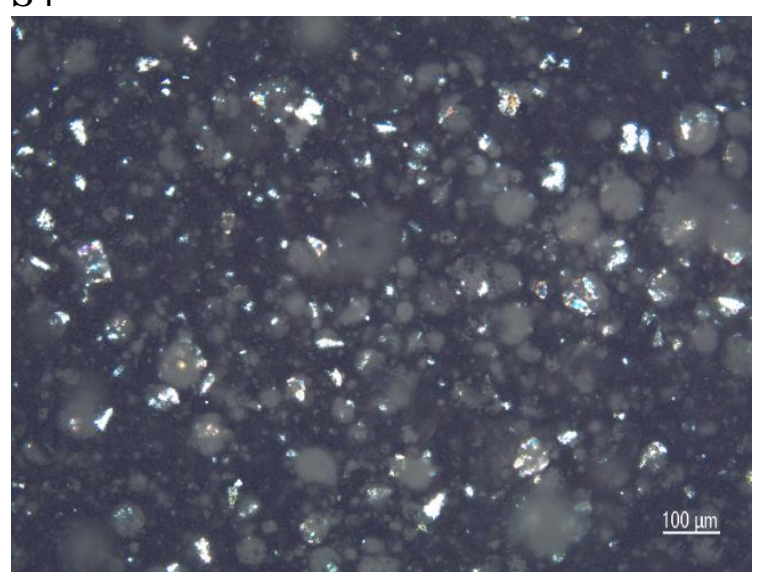

1
2

3

4

5

6

7

8

9
10

Figure 1 
Figure 2

14
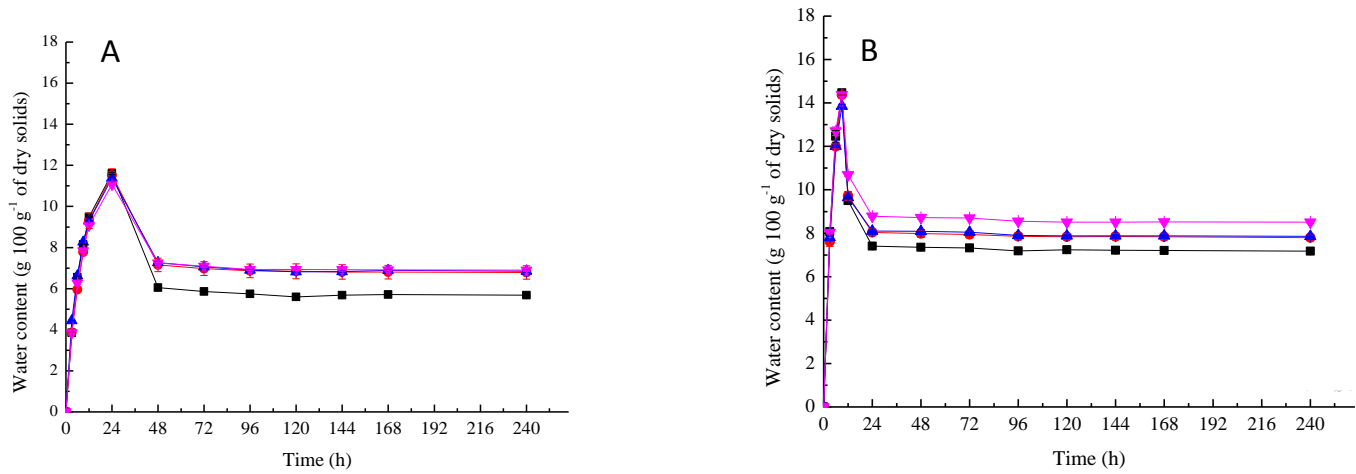

15

16

17

18

19

20

21

22

24

Figure 2 


\section{Figure 3}

A

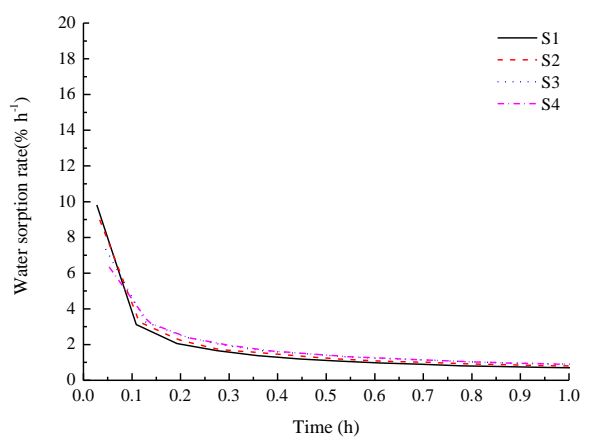

C

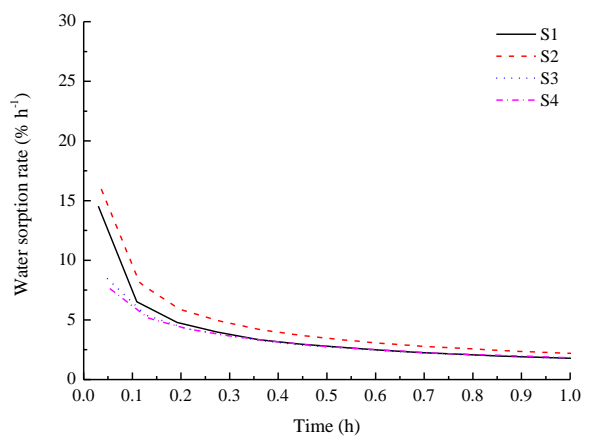

E

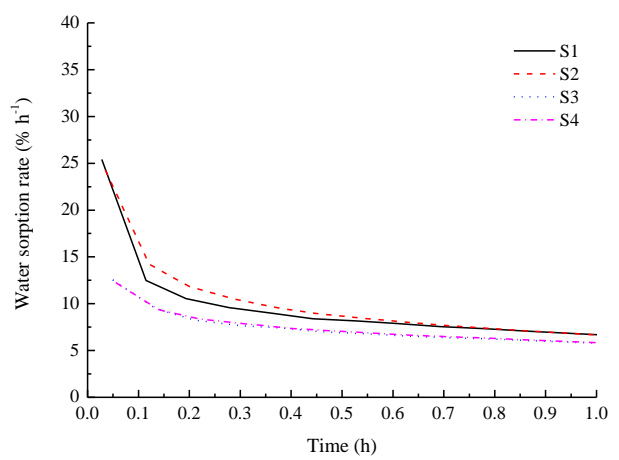

B

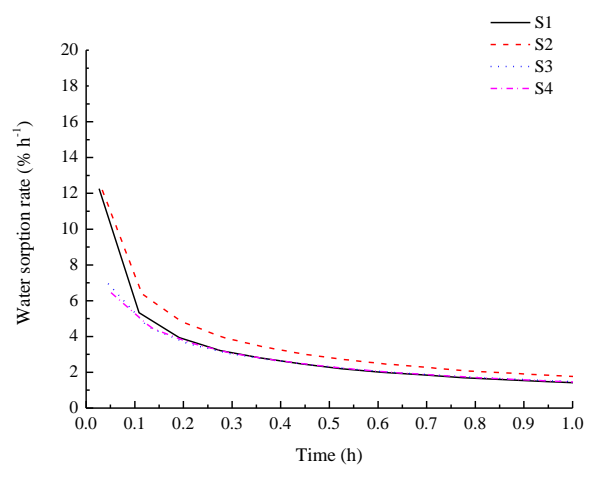

D

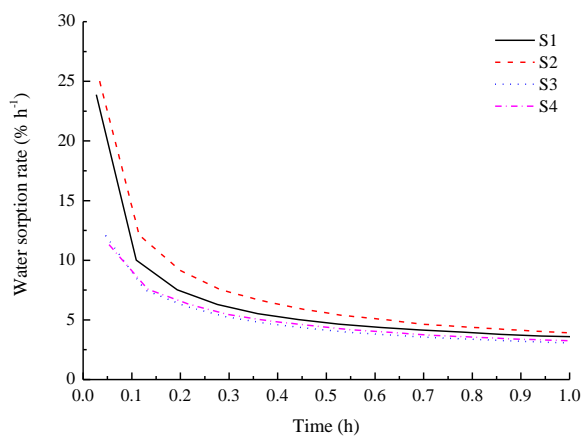

F

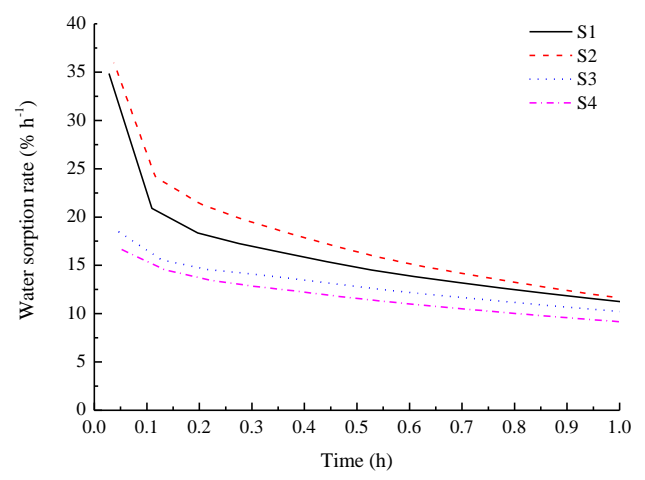

Figure 3 
A

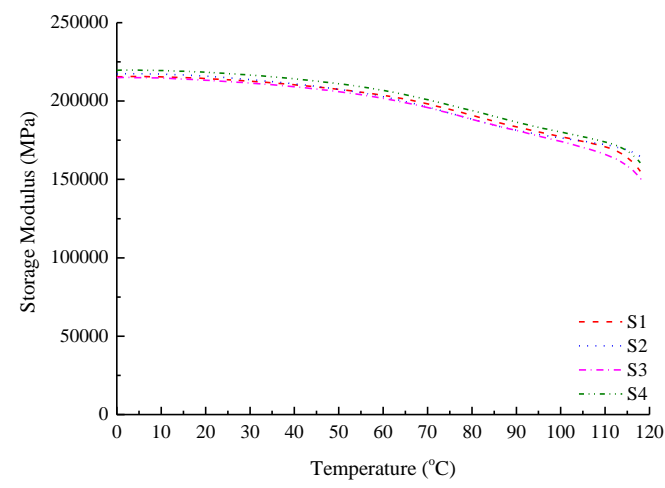

C

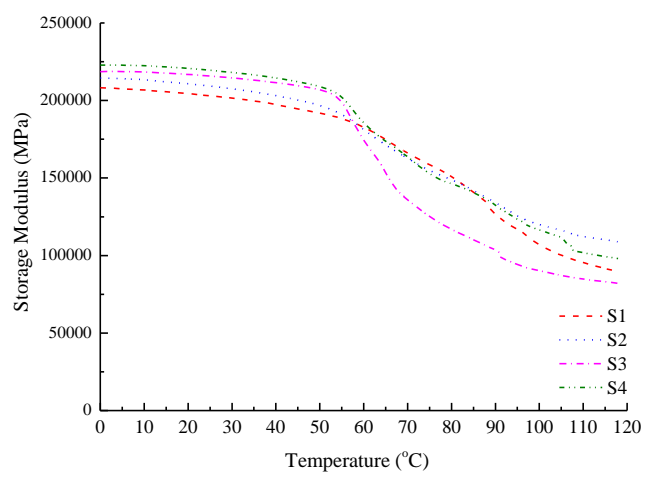

E

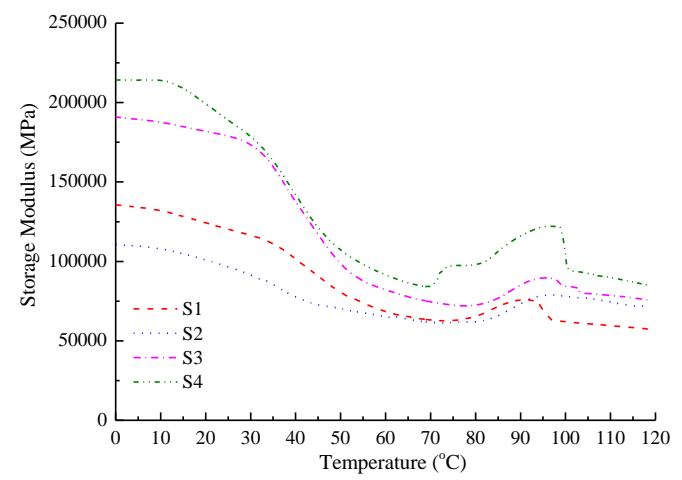

B

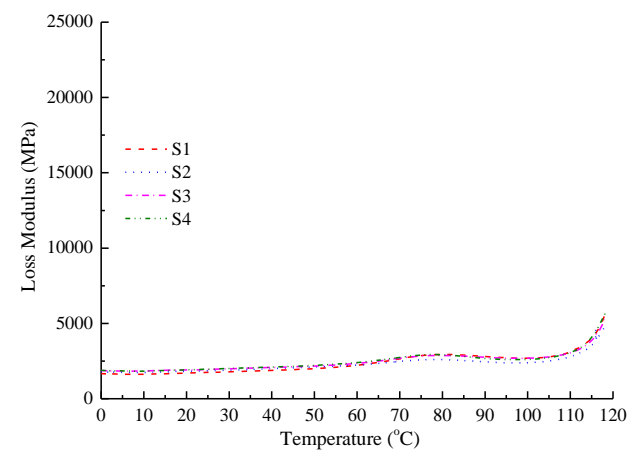

D

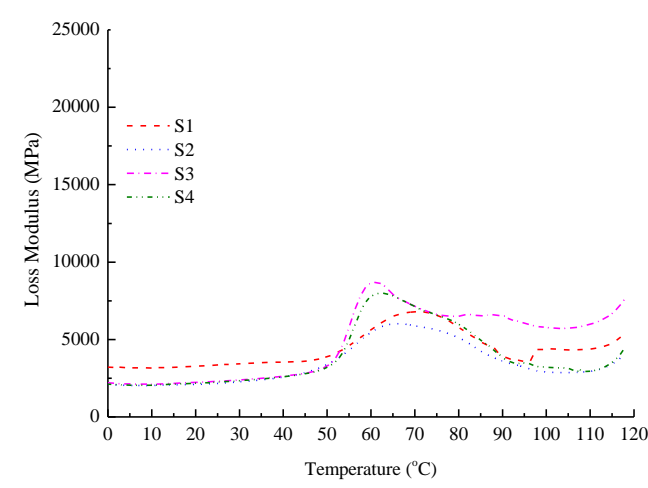

F

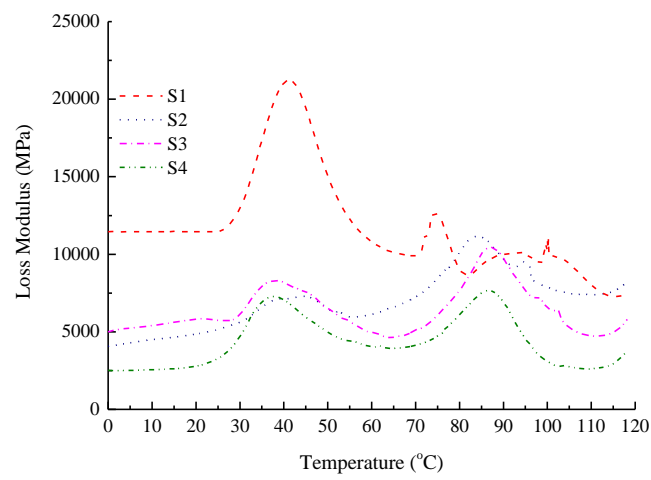

30

31

32

33

34

35

36

Figure 4 
Figure 5

A

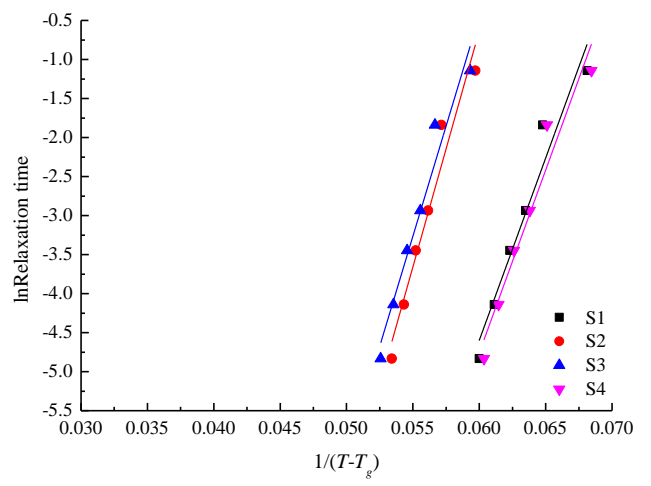

B

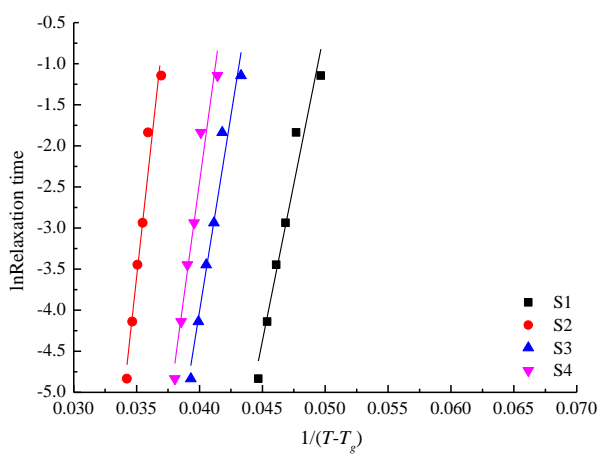

C

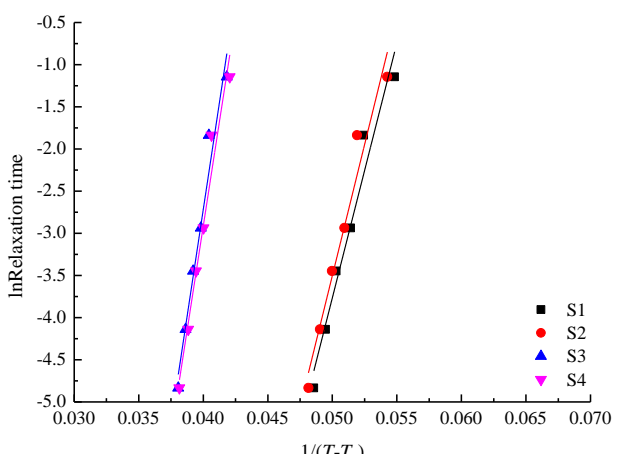

37

38

39

40

41

Figure 5 